\title{
Plant asymmetric cell division regulators: pinch-hitting for PARs?
}

\section{Carrie A Metzinger and Dominique C Bergmann*}

\author{
Address: Department of Biology, 371 Serra Mall, Stanford University, Stanford, CA, 94305-5020, USA \\ *Corresponding author: Dominique C Bergmann (dbergmann@stanford.edu) \\ FI000 Biology Reports 2010, 2:25 (doi:10.34I0/B2-25) \\ The electronic version of this article is the complete one and can be found at: http://fl000.com/reports/biology/content/2/25
}

\begin{abstract}
Like animals, plants use asymmetric cell divisions to create pattern and diversity. Due to a rigid cell wall and lack of cell migrations, these asymmetric divisions incur the additional constraints of being locked into their initial orientations. How do plants specify and carry out asymmetric divisions? Intercellular communication has been suspected for some time and recent developments identify these signals as well as point to segregated determinants and proteins with PAR-like functions as parts of the answer.
\end{abstract}

\section{Introduction and context}

Dividing asymmetrically is a complicated task for eukaryotic cells. The cell must generally define an axis, localize fate determinants, and coordinately orient the mitotic spindle. Both plant and animal cells must accomplish these tasks, but unlike animal cells, plant cells are surrounded by a cell wall that impedes cell movement. In most plant cell types, the future division plane is set, not by the spindle midzone position, but by the position of another cytoskeletal array. This array, the pre-prophase band (PPB), acts prior to mitosis and spindle assembly [1]. In the plant male germline, asymmetric divisions involve microtubule-dependent nuclear migration and a unique microtubule array at the future germ pole [2]. These mechanical features make asymmetric divisions, and the orientation of those divisions, particularly important for generating the overall cell pattern during plant development and indicate that plants may have needed to develop distinct methods for generation of cell asymmetry.

Asymmetric divisions are universally used to create cellular diversity and allow stem cell self-renewal. Four well-studied plant developmental contexts - the embryo, root meristem, the epidermal stomatal lineage, and the male germline - exemplify key functions of asymmetric divisions (Figure 1). The creation of cellular diversity by asymmetric division begins during Arabidopsis embryogenesis when the first zygotic division generates a small apical cell (the progenitor of most of the embryo) and a large basal cell (the future extra-embryonic suspensor) [3]. Asymmetric or oriented divisions are associated with the generation of major tissue layers; they also create what will later become the stem cell niche of the root when an asymmetric division of the hypophyseal cell yields a large basal daughter cell that generates the columella stem cells and a small apical cell that will give rise to the quiescent center (QC). The QC consists of a group of mitotically inactive cells that maintain adjacent stem cells [4]. Plants continue producing organs post-embryonically; much of this growth initiates from activities of the stem cell pools in the root and shoot; however, asymmetric divisions are also vital for de novo generation of cell lineages and patterns, as seen during stomatal development. Here, precursor cells of the stomatal lineage are generated by asymmetric divisions of meristemoid mother cells (MMCs) that are chosen, seemingly at random, from a field of equivalent protodermal cells. The daughters of the division include a stem cell-like meristemoid and a larger stomatal lineage ground cell (SLGC). The meristemoid, after completing a limited number of selfrenewing asymmetric divisions, will differentiate into a guard mother cell and then divide symmetrically to form a pair of stomatal guard cells. Although the SLGCs often differentiate into 'default' epidermal cells, they can also 
Figure I. Examples of asymmetric cell divisions during Arabidopsis development

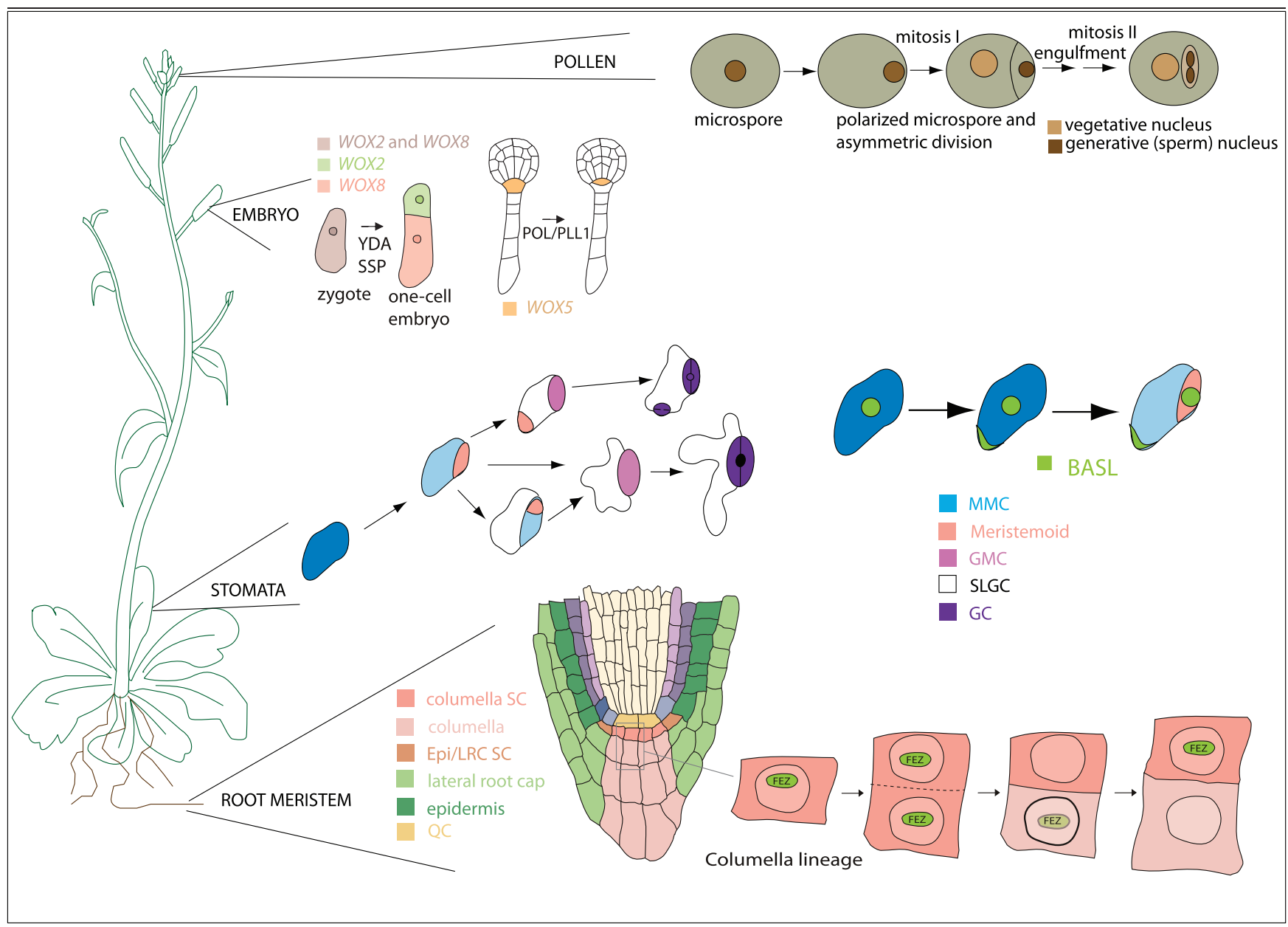

BASL, BREAKING OF ASYMMETRY IN THE STOMATAL LINEAGE; Epi, epidermis; GC, ground cell; GMC, guard mother cell; LRC, lateral root cap; MMC, meristemoid mother cell; PLLI, POLTERGEIST-LIKE I; POL, POLTERGEIST; QC, quiescent center; SC, stem cell; SLGC, stomatal lineage ground cell; SSP, SHORT SUSPENSOR; WOX, WUSCHEL-related homeobox; YDA, YODA. Figure modified from Abrash \& Bergmann, Dev Cell 2009 [22].

re-enter an asymmetric division phase, become MMCs, and produce satellite meristemoids whose positions are coordinated with neighbor cells through precise orientation of their asymmetric divisions [5]. Plants again employ intrinsically asymmetric divisions during male germline formation; here, an asymmetric division of the haploid microspore generates two unequally sized daughter cells: a non-germline vegetative cell that exits the cell cycle and a germ cell that divides again to form twin sperm cells for each pollen grain [6].

A unifying tenet of asymmetric cell division is that it generates two daughter cells with distinct fates. There are a number of ways that this endpoint can be reached, with some mechanisms requiring the establishment of polarities before division and others acting to influence the behavior of the daughters afterward. Screens for polarity regulators in animals led to the identification of the partitioning defective (PAR) proteins, the most conserved of which act in an asymmetrically localized cortical complex that establishes cell polarity and segregates fate determinants, thereby influencing the physical and fate asymmetries of daughter cells [7]. Homologues of the PARs are not found in plant genomes. Do plants use different proteins for analogous PAR-like functions? Here, we take individual elements of the PAR paradigm the ability to promote asymmetric fates, polarized localization within dividing cells, and roles in segregating fate determinants - and discuss recent results from studies of plant embryos, roots, stomata, and pollen in reference to these behaviors and functions (Figure 2).

\section{Major recent advances}

Mutations in several genes lead to defects in specifying or maintaining unequal daughter cell fates. The asymmetric division that creates the embryo and suspensor requires 
Figure 2. Animal and plant proteins that demonstrate various elements of asymmetric division

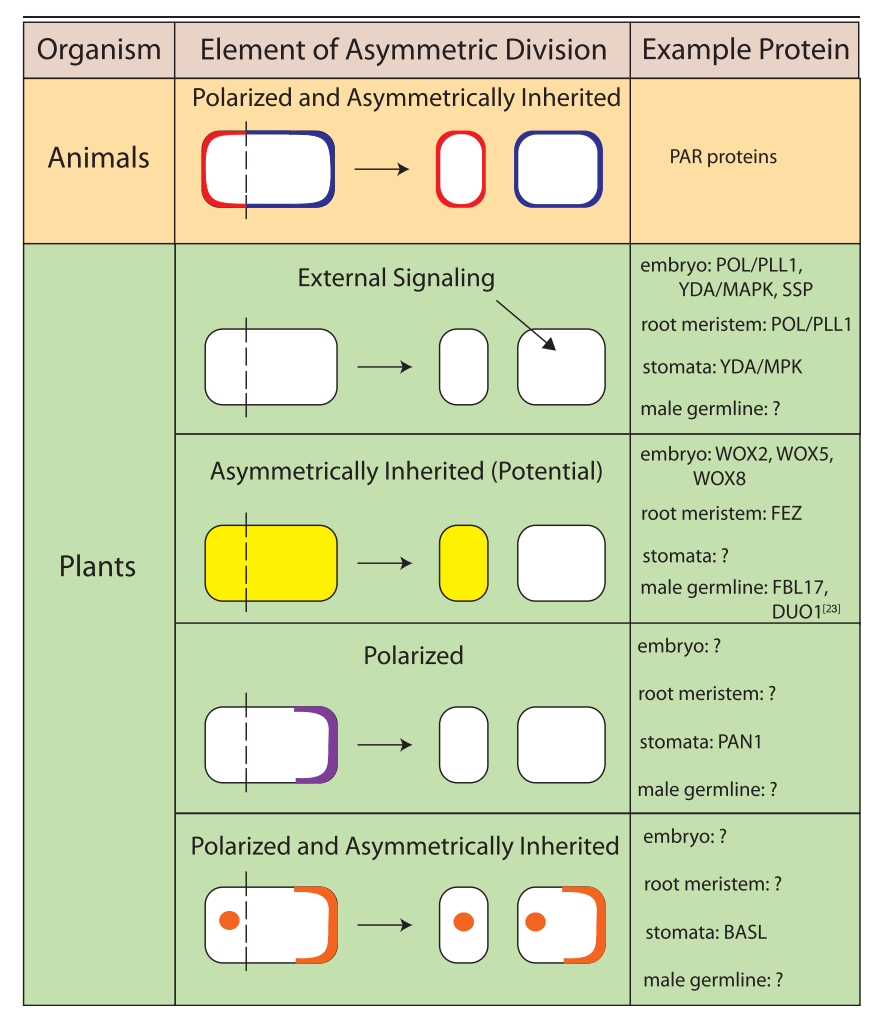

BASL, BREAKING OF ASYMMETRY IN THE STOMATAL LINEAGE; DUOI, duo pollen I; FBLI7, F-box like protein 17; MAPK, mitogenactivated protein kinase; MPK, Arabidopsis gene encoding a mitogenactivated protein kinase; PANI, PANGLOSS I; PAR, partitioning defective; PLLI, POLTERGEIST-LIKE I; POL, POLTERGEIST; SSP, SHORT SUSPENSOR; WOX, WUSCHEL-related homeobox; YDA, YODA.

mitogen-activated protein kinase (MAPK) signals, including core cascade elements YODA (YDA), a MAPK kinase kinase [8], MPK3 and MPK6 (MAPKs) [9], and a spermsupplied upstream regulator, SHORT SUSPENSOR (SSP), which activates MAPK signaling in the zygote [10]. Mutations in these components equalize presumptive embryo and suspensor cell sizes and identities. In the later hypophyseal division, two type $2 \mathrm{C}$ protein phosphatases, POLTERGEIST (POL) and POLTERGEIST-LIKE 1 (PLL1), are redundantly required to generate asymmetry; in $\mathrm{pol} / \mathrm{pll1}$ mutants, the hypophyseal division occurs symmetrically and neither of the resulting daughter cells adopts the appropriate fate [11]. There is some evidence for re-use of these putative signaling elements; for example, POL and PLL1 are used for the establishment of other stem cell populations [11] and the MAPK cascades are used again for stomatal divisions $[9,12]$. Later stomatal decisions also require unique regulators such as BREAKING OF ASYMMETRY IN THE STOMATAL LINEAGE (BASL); when BASL is present, only $12 \%$ of meristemoids or MMCs divide asymmetrically, with the daughter cells often adopting the same fate [13].

POL/PLL1, SSP, YDA, and MPK3/6 are likely to be elements of pathways that lead to the appropriate timing or placement of divisions (or both) in response to information originating from outside of the asymmetrically dividing cell. This is consistent with the long-held view that plant cells derive their identity primarily by position (reinforced by cell-cell communication, for example [14]). However, it is now clear that intrinsic mechanisms like unequal inheritance of proteins are also likely to contribute to generating daughter cells with different fates. Transcripts of WUSCHEL-related homeobox 2 (WOX2) and WOX8, members of the homeodomain transcription factor family, while initially expressed throughout the zygote, are apparent in only the apical and basal cell, respectively, after its asymmetric division $[15,16]$. Similarly, WOX5 is expressed in the hypophyseal cell but after division is found in only the apical daughter cell [16]. In the root meristem, the NAC (NAM, ATAF1/2, and CUC2) domain transcription factor FEZ promotes the asymmetric division of columella stem cells and displays a dynamic localization pattern in both the stem cells and their daughters. FEZ protein is in pre-division stem cells, but immediately after division, the 'stem cell' daughters lack FEZ while their terminally differentiating sisters express FEZ; FEZ expression is only later reestablished in the daughters with stem cell identity [17]. In male germline formation, transcripts of the F-box protein FBL17 are expressed in the microspore but the FBL17 protein is expressed only in the germ cell following asymmetric division [18]. While FEZ, members of the WOX family, and FBL17 show differential expression following asymmetric division, their subcellular localization and dynamics during the entire division process have not yet been reported; thus, we do not know whether any of these proteins are truly differentially segregated. Their molecular identities are also not easily reconciled with a direct role generating intrinsic cellular polarities.

If we take the cue from the PARs that polarity-generating proteins will exhibit polarized expression at the cell cortex, then what are the plant candidates? The pinformed (PIN) family of auxin transporters is tied to cellular and organismal polarity generation and several of these proteins are localized to a single face of a cell (reviewed in [19]); however, there is scant evidence that the PINs are segregated during asymmetric divisions. Maize PANGLOSS1 (PAN1), a receptor-like protein, is highly polarized in stomatal lineage cells that will undergo asymmetric division, pointing to a possible role in generating pre-divisional asymmetry [20]. It is 
not clear, however, whether PAN1 is asymmetrically inherited [20]. Another stomatal protein, BASL, is both polarized and asymmetrically inherited. Prior to an asymmetric cell division in meristemoid cells or MMCs, BASL is both nuclear and in a polarized peripheral crescent [13]. Immediately following asymmetric division, BASL can be found in the nucleus of the smaller cell and at the periphery as well as the nucleus of the larger daughter cell, with the main activity of BASL being ascribed to the peripheral pool [13]. Ectopic expression of BASL produces a localized zone of cellular outgrowth but does not appear to alter cell fates; thus, it too fails to behave in a manner completely analogous to the PARs. It is not known how the domain of peripheral BASL is established or whether BASL generates or responds to an earlier cellular polarity; interestingly, this polarity is likely transient because the BASL crescent disappears from one site and is reestablished in a new polar crescent in redividing SLGCs [13].

\section{Future directions}

Unlike in animal systems where the PAR proteins coordinate multiple aspects of asymmetric division in many developmental contexts, in examples from the germline, embryos, meristems, and stomata, we see a great diversity of regulators. Are there specific aspects of these different plant cell divisions that necessitate different controls? Or will homologues of regulators from one context participate in others? In each of these cases, what is the connection between developmental specification of asymmetry and the execution of oriented division? Several proteins have recently been shown to translate the position of the PPB into the subsequent new wall position $[1,21]$, but virtually nothing is known about how the positions of the PPB and division plane are specified. Can we identify the targets of the transcription factor families or connect the highly polarized proteins (BASL and PAN1) in a mechanistic way to the process of PPB placement?

After their discovery, the PARs became an intellectual scaffold for considering other asymmetric cell division proteins. Future plant studies should be guided by the constant consideration of both the logical insights from the PARs and by the unique constraints of plant development.

\section{Abbreviations}

BASL, BREAKING OF ASYMMETRY IN THE STOMATAL LINEAGE; FBL17, F-box like protein 17; MAPK, mitogenactivated protein kinase; MMC, meristemoid mother cell; PAN1, PANGLOSS1; PAR, partitioning defective; PIN, pinformed; PLL1, POLTERGEIST-LIKE 1; POL, POLTERGEIST; PPB, pre-prophase band; QC, quiescent center; SLGC, stomatal lineage ground cell; SSP, SHORT SUSPENSOR; WOX, WUSCHEL-related homeobox; YDA, YODA.

\section{Competing interests}

The authors declare that they have no competing interests.

\section{Acknowledgments}

Work on asymmetric cell divisions in the authors' lab is supported by the National Science Foundation (IOS 0845521) and the National Institutes of Health (R01GM086632).

\section{References}

I. Wright A, Smith L: Division plane orientation in plant cells. In Cell Division Control in Plants. Edited by Verma DPS, Hong Z. Berlin, Germany: Springer-Verlag; 2008:33-57.

2. Oh SA, Pal MD, Park SK, Johnson JA, Twell D: The tobacco MAP2/5/Disl-family protein TMBP200 is required for the functional organization of microtubule arrays during male germline establishment. J Exp Bot 2010, 61:969-81.

3. Jenik PD, Gillmor CS, Lukowitz W: Embryonic patterning in Arabidopsis thaliana. Annu Rev Cell Dev Biol 2007, 23:207-36.

4. Scheres B, Benfey P, Dolan L: Root development. In The Arabidopsis Book. Edited by Somerville CR, Meyerowitz EM. Rockville, MD: American Society of Plant Biologists; 2002.

5. Bergmann DC, Sack FD: Stomatal development. Annu Rev Plant Biol 2007, 58: |63-8I.

6. Borg M, Brownfield L, Twell D: Male gametophyte development: a molecular perspective. J Exp Bot 2009, 60:1465-78.

7. Goldstein B, Macara IG: The PAR proteins: fundamental players in animal cell polarization. Dev Cell 2007, I 3:609-22.

8. Lukowitz W, Roeder A, Parmenter D, Somerville C: A MAPKK kinase gene regulates extra-embryonic cell fate in Arabidopsis. Cell 2004, I 16:109-19.

FI000 Factor 6.5 Must Read

Evaluated by Jen Sheen 09 Jan 2004, Robert Sablowski 20 Feb 2004, Philip Benfey 16 Mar 2004

9. Wang H, Ngwenyama N, Liu Y, Walker JC, Zhang S: Stomatal development and patterning are regulated by environmentally responsive mitogen-activated protein kinases in Arabidopsis. Plant Cell 2007, 19:63-73.

10. Bayer M, Nawy T, Giglione C, Galli M, Meinnel T, Lukowitz W: Paternal control of embryonic patterning in Arabidopsis thaliana. Science 2009, 323:|485-8.

FI000 Factor 10.6 Exceptional

Evaluated by Rüdiger Simon 20 Mar 2009, Christian Hardtke 20 Mar 2009, Kay Schneitz 20 Mar 2009, Arp Schnittger 06 Apr 2009, Thierry Gaude 22 Apr 2009, Dominique Bergmann II May 2009

II. Song SK, Hofhuis H, Lee MM, Clark SE: Key divisions in the early Arabidopsis embryo require POL and PLLI phosphatases to establish the root stem cell organizer and vascular axis. Dev Cell 2008, 15:98-109.

FI000 Factor 6.5 Must Read Evaluated by Mark Running 18 Jul 2008, Robert Sablowski 24 Jul 2008, Jennifer Fletcher 31 Jul 2008

12. Bergmann DC, Lukowitz W, Somerville CR: Stomatal development and pattern controlled by a MAPKK kinase. Science 2004, 304: 1494-7.

FI000 Factor 6.7 Must Read

Evaluated by Takashi Hashimoto 10 Jun 2004, Elizabeth Kellogg 17 Jun 2004, Julian Schroeder 24 Jun 2004, Robert Sablowski 25 Jun 2004, Arp Schnittger 29 Jul 2004 
13. Dong J, MacAlister CA, Bergmann DC: BASL controls asymmetric cell division in Arabidopsis. Cell 2009, 137:1320-30.

FI000 Factor 8.2 Exceptional

Evaluated by Wolf B Frommer 25 Jun 2009, Elena Alvarez-Buylla 23 Jul 2009, Rüdiger Simon 12 Nov 2009

14. van den Berg C, Willemsen V, Hendriks G, Weisbeek P, Scheres B: Short-range control of cell differentiation in the Arabidopsis root meristem. Nature 1997, 390:287-9.

15. Breuninger H, Rikirsch E, Hermann M, Ueda M, Laux T: Differential expression of WOX genes mediates apical-basal axis formation in the Arabidopsis embryo. Dev Cell 2008, 14:867-76.

16. Haecker A, Gross-Hardt R, Geiges B, Sarkar A, Breuninger H, Herrmann M, Laux T: Expression dynamics of WOX genes mark cell fate decisions during early embryonic patterning in Arabidopsis thaliana. Development 2004, I 3 I:657-68

FI000 Factor 5.0 Must Read

Evaluated by Gwyneth Ingram 14 Jan 2004, Detlef Weigel 2I Jan 2004, Jan Traas 27 Jan 2004, Elizabeth Kellogg 05 Feb 2004

17. Willemsen V, Bauch M, Bennett T, Campilho A, Wolkenfelt $\mathrm{H}, \mathrm{Xu} \mathrm{J}$, Haseloff J, Scheres B: The NAC domain transcription factors FEZ and SOMBRERO control the orientation of cell division plane in Arabidopsis root stem cells. Dev Cell 2008, 15:9|3-22.

FI000 Factor 6.0 Must Read

Evaluated by Gwyneth Ingram 07 Jan 2009
18. Kim HJ, Oh SA, Brownfield L, Hong SH, Ryu H, Hwang I, Twell D, Nam HG: Control of plant germline proliferation by SCF (FBLI7) degradation of cell cycle inhibitors. Nature 2008, 455: II34-7.

FI000 Factor 6.0 Must Read

Evaluated by Daniel Chamovitz 25 Nov 2008

19. Geldner N: Cell polarity in plants: a PARspective on PINs. Curr Opin Plant Biol 2009, I 2:42-8.

20. Cartwright HN, Humphries JA, Smith LG: PANI: a receptor-like protein that promotes polarization of an asymmetric cell division in maize. Science 2009, 323:649-5I.

FI000 Factor 4.8 Must Read

Evaluated by Dominique Bergmann 04 Feb 2009, Liam Dolan 10 Feb 2009

21. Muller S, Wright AJ, Smith LG: Division plane control in plants: new players in the band. Trends Cell Biol 2009, 19:180-8.

22. Abrash EB, Bergmann DC: Asymmetric cell divisions: a view from plant development. Dev Cell 2009, 16:783-96.

23. Brownfield L, Hafidh S, Borg M, Sidorova A, Mori T, Twell D: A plant germline-specific integrator of sperm specification and cell cycle progression. PLoS Genet 2009, 5:e 1000430.

FI000 Factor 6.4 Must Read

Evaluated by Venkatesan Sundaresan I4 Apr 2009, Neelima Sinha 27 Apr 2009 